\title{
Prediction of Circulating Adipokine Levels Based on Body Fat Compartments and Adipose Tissue Gene Expression
}

\author{
Stefan Konigorskia, bürgen Janke ${ }^{a}$ Dagmar Drogan ${ }^{c}$ \\ Manuela M. Bergmann ${ }^{d}$ Johannes Hierholzere Rudolf Kaaks ${ }^{f}$ \\ Heiner Boeing ${ }^{d}$ Tobias Pischona, ${ }^{\mathrm{g}}, \mathrm{h}$ \\ a Molecular Epidemiology Research Group, Max Delbrück Center (MDC) for Molecular \\ Medicine in the Helmholtz Association, Berlin, Germany; ${ }^{b}$ Machine Learning Research \\ Group, Hasso Plattner Institute for Digital Engineering, Potsdam, Germany; ${ }^{\mathrm{C} A O K}$ Research

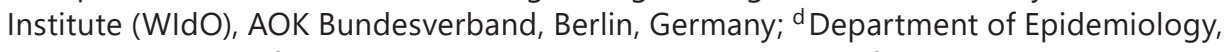 \\ German Institute of Human Nutrition Potsdam-Rehbrücke (DIfE), Nuthetal, Germany; \\ e Department of Diagnostic and Interventional Radiology, Clinic Ernst von Bergmann, \\ Potsdam, Germany; fDepartment of Cancer Epidemiology, German Cancer Research \\ Center (DKFZ), Heidelberg, Germany; ${ }^{9}$ Charité Universitätsmedizin Berlin, Berlin, Germany; \\ ${ }^{\mathrm{h}}$ German Center for Cardiovascular Research (DZHK) partner site Berlin, Berlin, Germany
}

\section{Keywords}

Adipokines · Magnetic resonance imaging scans · Anthropometric measures - Adipose tissue gene expression · Cross-sectional study

\begin{abstract}
Background: Adipokines are hormones secreted from adipose tissue (AT), and a number of them have been established as risk factors for chronic diseases. However, it is not clear whether and to what extent adiposity, gene expression, and other factors determine their circulating levels. Objectives: To assess to what extent adiposity, as measured by the amount of subcutaneous AT (SAT) and visceral AT (VAT) using magnetic resonance imaging, and gene expression levels in SAT determine plasma concentrations of the adipokines adiponectin, leptin, soluble leptin receptor, resistin, interleukin 6, and fatty acid-binding protein 4 (FABP4). Methods: We performed a cross-sectional analysis of 156 participants from the EPIC Potsdam cohort study and analyzed multiple regression models and partial correlation coefficients. Results: For leptin and FABP4 concentrations, 81 and $45 \%$ variance were explained by SAT mass, VAT mass, and gene expression in SAT in multivariable regression models. For the remaining adipokines, AT mass and gene expression explained $<16 \%$ variance of plasma concentrations. Gene expres-
\end{abstract}


Konigorski et al.: Prediction of Circulating Adipokine Levels Based on Body Fat

Compartments and Adipose Tissue Gene Expression

sion in SAT was a less important predictor compared to AT mass. SAT mass was a better predictor than VAT mass for leptin (partial correlation $r=0.81,95 \%$ confidence interval $0.75-0.86$, vs. $r=0.58,95 \%$ confidence interval 0.46-0.67), while differences between AT compartments were small for the other adipokines. Conclusions: While plasma levels of leptin and FABP4 can be explained in a large and medium part by the amount of AT and SAT gene expression, surprisingly, these predictors explained only little variance for all other investigated adipokines.

(C) 2019 The Author(s)

Published by S. Karger AG, Basel

\section{Introduction}

Obesity is an established risk factor for a number of chronic diseases. It is conceptually defined as a condition of abnormal or excessive body fat accumulation to the extent that health may be impaired [1]. In line with this, investigations into the underlying molecular processes have identified circulating adipose tissue (AT)-derived biomarkers, so-called adipokines, that are - among various pathways - involved in glucose and lipid metabolism, inflammation, insulin signaling, and energy homeostasis [2-4]. A number of these adipokines have also been associated with risk of cardiovascular disease, diabetes, hypertension, and cancer, and have been proposed as mediators for the association of obesity with chronic disease risk [3,5-8]. Prominent examples are leptin $[5,9]$, the soluble leptin receptor (sOB-R) $[5,10]$, adiponectin with its different circulating molecular forms $[4,6]$, interleukin 6 (IL-6) $[4,11,12]$, fatty acid-binding protein 4 (FABP4) $[11]$, and resistin $[13,14]$, which are the focus of this study. Yet, the variance of their plasma levels explained by body mass index (BMI) or by waist circumference (WC) - which are currently used to classify obesity or abdominal obesity, respectively - was found to be relatively modest: around $36 \%$ for leptin and only up to $10 \%$ for most of the other adipokines $[4,5,8]$. One reason for this observation may be that BMI and WC are only crude measures of the amount of subcutaneous AT (SAT) and visceral AT (VAT), which are the major compartments of human AT [15] and purportedly the major source of most adipokines. SAT and VAT have established anatomical, cellular, molecular, physiological, metabolic, and endocrinological differences [15-17].

Magnetic resonance imaging (MRI) allows direct quantification of total AT (TAT), SAT, and VAT [18], but there is inconsistent empirical evidence as to what extent imaging-based assessment of VAT, SAT, or TAT determines adipokine levels [19-21]. Also, the gene expression in these tissues has often not been taken into account as a further predictor of plasma levels of these adipokines. Only few studies have reported on the association of imaging-based AT mass with gene expression and plasma or serum concentrations [22-37], and they have mostly investigated small study samples and focused on specific patient groups or the effect of interventions and the analysis of one or two candidate adipokines.

The aim of our study was therefore to investigate to which extent plasma levels of the above six adipokines are determined by the amount of SAT and VAT assessed by MRI and by gene expression measured in SAT. Our hypothesis was that direct quantification of SAT and VAT as well as gene expression in AT can explain a substantial amount of the variance in adipokine levels. In secondary analyses, we investigated additional predictors and compared the role of body fat compartments and gene expression in more detail.

\section{Materials and Methods}

\section{Study Population}

This study was conducted in a subcohort of EPIC Potsdam within the large European Prospective Investigation into Cancer and Nutrition (EPIC) study [38, 39]. EPIC Potsdam is 
Konigorski et al.: Prediction of Circulating Adipokine Levels Based on Body Fat Compartments and Adipose Tissue Gene Expression

an ongoing cohort study among 27,548 persons aged 35-65 years at recruitment between 1994 and 1998 from the general population of the city of Potsdam and the surrounding area in Germany. From 2010 to 2013, a random sample of 1,472 participants was reinvited to the study center. Inclusion criteria were the absence of severe disease within the previous year (e.g., cancer, myocardial infarction, stroke), not being a wheelchair user, and not having had surgery within 3 months prior to the examination. A total of 815 participants attended the reexamination and completed a detailed study protocol including the collection of blood samples and assessment of lifestyle factors, regular medication use, blood pressure, and standard anthropometric measures according to standardized protocols following the WHO guidelines [40] (online suppl. text S1; for all online suppl. material, see www.karger.com/doi/10.1159/000502117). MRI scans were obtained to assess body compartments from 594 participants on a separate visit (online suppl. text S2), scheduled within a maximum interval of 4 weeks from the initial visit (average difference 25 days). SAT biopsies were taken from 278 participants using a needle aspiration method, with sufficient material extracted from 200 participants (online suppl. text S3). For 156 of the 200 participants, MRI measurements and plasma samples are available, and they therefore constituted the sample for this study. In comparison to the full EPIC Potsdam cohort, these 156 probands were very similar regarding age and sex distribution, disease prevalence, and anthropometric measures (data not shown). Sex was set to equal the assessed gender.

\section{Assessment of AT Mass}

Body fat measures were obtained from the whole-body MRI scans using a fully automated segmentation approach, which provided very similar estimates compared to a manual expert segmentation and had high repeatability and reproducibility of the measurements (coefficient of variation $=0.4 \%$ for SAT and TAT and $3.5 \%$ for VAT $[41,42]$; online suppl. text S2). Available measures include the amount of AT in the visceral compartment (in the abdominal cavity, i.e., around and between the organs in the abdomen), the subcutaneous compartment (fat tissue beneath the skin), and the coronary compartment (fat tissue around the heart and heart vessels in the thorax; coronary AT [CAT]) (see online suppl. text S2 for more details). TAT was calculated as the sum of VAT, SAT, and CAT. Additionally, the amount of skeletal muscle tissue (SMT) and total body volume were assessed. The AT/height [43], AT/height ${ }^{2}$ (= fat mass index [44]), and AT/height ${ }^{3}$ [43] ratios were computed for VAT, SAT, CAT, and TAT as measures of AT mass standardized by height, and AT/SMT was investigated to address the capacity-load model [45] to set AT mass in relation to SMT.

Assessment of Biomarker Plasma Levels and SAT Gene Expression

EDTA plasma levels of total, high molecular weight (HMW), and HMW + medium molecular weight (MMW) adiponectin were measured using ELISAs from ALPCO (Salem, NH, USA), and concentrations of MMW and low molecular weight (LMW) adiponectin computed by subtraction. Leptin, sOB-R, resistin, and FABP4 were measured using ELISAs from BioVendor (Brno, Czech Republic), and IL-6 was measured using an ELISA from R\&D Systems (Minneapolis, MN, USA). All samples were measured in duplicate according to the standard protocol on the TECAN Infinite 200 PRO reader (Männedorf, Switzerland) and had small inter- and intra-assay coefficients of variation (online suppl. text S4).

Quantitative real-time polymerase chain reaction (PCR) was performed using the Applied Biosystems 7500 Fast Real-time PCR system with TaqMan technology (ABI, Darmstadt, Germany) to evaluate the gene expression in SAT of the target genes adiponectin, leptin, sOB-R, resistin, IL-6, and FABP4 (online suppl. text S5). For each sample and for each gene, 
Konigorski et al.: Prediction of Circulating Adipokine Levels Based on Body Fat

Compartments and Adipose Tissue Gene Expression

gene expression was measured in triplicate and the three $\mathrm{Ct}$ values were averaged for each individual. As measure for gene expression in all analyses $2^{-\Delta C t}$ values were used, assuming that the number of amplified target molecules at the threshold cycle is identical for the candidate genes and the measured housekeeper gene 18S [46]. All experiments had small inter- and intra-assay coefficients of variation.

\section{Statistical Analysis}

Statistical analyses were performed using R version 3.3.1 [47]. All gene expression, plasma concentration, and MRI-based measures of AT mass (including the AT/height, AT/ height ${ }^{2}$, AT/height ${ }^{3}$, and AT/SMT ratios) were log-transformed to yield normally distributed measures for the analysis. All analyses are based on the sample of 156 participants, with the exception of analyses that include leptin, FABP4, and LMW adiponectin concentrations, which each have one missing value.

For our main aim, we fitted multiple linear regression models and calculated the adjusted $R^{2}$ to assess how much of the variance of plasma concentrations can be explained by AT compartments and gene expression. For each adipokine, these models included the following predictors in different combinations: SAT gene expression (of the respective gene), SAT mass, VAT mass, and the interaction of SAT mass with SAT gene expression (of the respective gene). The interaction can be interpreted as the amount of tissue (i.e., number and size of cells) multiplied by the cell-based measure of transcriptomic activity. The adjusted $R^{2}$ of each regression model is the total variance explained by all predictors in the model, adjusted for the number of included predictors.

We were also interested whether other predictors further increase the explained variance in adipokine concentrations. Men and women differ in their amount of AT, hence sex is expected to contribute to the variance in SAT and VAT mass. Therefore, we examined the amount of variance of adipokine concentrations explained by sex, as a single predictor as well as together with SAT gene expression of the corresponding gene, SAT mass, and VAT mass. In additional analyses we added the following predictors in different combinations to the regression model: age, occupational training, physical activity, employment status, partner status, smoking status, socioeconomic status, history of diabetes, BMI, waist-hip ratio, CAT, TAT, and gene expression and plasma concentrations of all other adipokines considered in our study (see Tables 2 and 3 for a detailed description of the regression models).

Although these models may not allow a valid separation of the effects of the different predictors, they provide a helpful quantification of the overall explained variance by body compartments, gene expression, and other predictors since any adjusted analysis also removes part of the variance of adipokine levels or AT compartments. In addition to these variance analyses, we also examined partial Pearson correlation coefficients of the plasma concentrations with AT measures and gene expression, adjusted for sex, age, physical activity, and occupational training. These covariates were chosen based on conceptual reasoning that they might act as confounders in the correlation analyses. For example, AT mass varies between the sexes, AT mass and adipokine levels change over the life course and by physical activity, and occupational training seemed to be the best proxy for socioeconomic status in our analyses, which has been shown to be associated with obesity.

For sensitivity analyses, we performed sex-stratified analyses, repeated the main analyses using an estimate of the absolute quantity of adipokine molecules in plasma (instead of plasma concentrations), and also computed analyses based on AT/height, AT/height ${ }^{2}$, AT/height ${ }^{3}$, as well as AT/SMT, which all yielded almost identical results (online suppl. text S6). 
Konigorski et al.: Prediction of Circulating Adipokine Levels Based on Body Fat Compartments and Adipose Tissue Gene Expression

Table 1. Sex-stratified characteristics of the study population

\begin{tabular}{|c|c|c|c|}
\hline Measures & Women & Men & $p$ value \\
\hline Sample size & 86 & 70 & - \\
\hline Age, years & $62.7(8.4)$ & $66.8(8.3)$ & $2.8 \times 10^{-3}$ \\
\hline Smoking 4 & & & $2.3 \times 10^{-3}$ \\
\hline Never & $54.7 \%$ & $28.6 \%$ & \\
\hline Former & $31.4 \%$ & $57.1 \%$ & \\
\hline Current & $14.0 \%$ & $14.3 \%$ & \\
\hline $\mathrm{CPAI}^{4}$ & & & 0.99 \\
\hline Inactive & $8.1 \%$ & $8.6 \%$ & \\
\hline Moderately inactive & $26.7 \%$ & $28.6 \%$ & \\
\hline Moderately active & $34.9 \%$ & $34.3 \%$ & \\
\hline Active & $30.2 \%$ & $28.6 \%$ & \\
\hline Occupational training ${ }^{4}$ & & & $8.8 \times 10^{-3}$ \\
\hline No vocational training/vocational training & $40.7 \%$ & $32.9 \%$ & \\
\hline Technical college & $25.6 \%$ & $11.4 \%$ & \\
\hline University & $32.6 \%$ & $55.7 \%$ & \\
\hline Systolic blood pressure, $\mathrm{mm} \mathrm{Hg}$ & $132.6(15.2)$ & $137.5(16.2)$ & 0.05 \\
\hline Diastolic blood pressure, $\mathrm{mm} \mathrm{Hg}$ & $79.5(9.7)$ & $81.9(10.1)$ & 0.15 \\
\hline Myocardial infarction ${ }^{5}$ & $0 \%$ & $1.4 \%$ & 0.45 \\
\hline Stroke & $0 \%$ & $0 \%$ & - \\
\hline Heart failure & $0 \%$ & $0 \%$ & - \\
\hline Diabetes $^{5}$ & $1.2 \%$ & $10.0 \%$ & $1.6 \times 10^{-2}$ \\
\hline \multicolumn{4}{|l|}{ Medication use } \\
\hline Blood pressure-lowering drugs ${ }^{4}$ & $38.4 \%$ & $47.1 \%$ & 0.35 \\
\hline Cholesterol-/triglyceride-lowering drugs ${ }^{4}$ & $17.4 \%$ & $21.4 \%$ & 0.67 \\
\hline Anti-inflammatory drugs ${ }^{5}$ & $8.1 \%$ & $7.1 \%$ & 1 \\
\hline Antidiabetic drugs ${ }^{5}$ & $2.3 \%$ & $10.0 \%$ & 0.08 \\
\hline \multicolumn{4}{|l|}{ Standard anthropometric measures } \\
\hline Height, cm & $161.9(5.5)$ & $175.0(6.1)$ & $2.3 \times 10^{-28}$ \\
\hline Weight, kg & $72.9(11.4)$ & $85.5(11.1)$ & $9.5 \times 10^{-11}$ \\
\hline Body mass index, $\mathrm{kg} / \mathrm{m}^{2}$ & $27.8(4.3)$ & $28.0(3.9)$ & 0.81 \\
\hline Waist circumference, $\mathrm{cm}$ & $91.6(10.3)$ & $102.3(10.0)$ & $7.6 \times 10^{-10}$ \\
\hline Hip circumference, $\mathrm{cm}$ & $106.2(9.6)$ & $102.3(6.4)$ & $3.4 \times 10^{-3}$ \\
\hline Waist-hip ratio & $0.9(0.1)$ & $1.0(0.1)$ & $4.8 \times 10^{-30}$ \\
\hline \multicolumn{4}{|l|}{ MRI AT measures ${ }^{1,3}$} \\
\hline VAT, kg & $2.9(1.1)$ & $5.2(1.6)$ & $9.3 \times 10^{-14}$ \\
\hline CAT, kg & $0.3(0.1)$ & $0.4(0.2)$ & $3.2 \times 10^{-13}$ \\
\hline SAT, kg & $20.1(5.1)$ & $14.7(4.3)$ & $1.2 \times 10^{-12}$ \\
\hline TAT, kg & $23.7(5.4)$ & $20.7(5.8)$ & $1.0 \times 10^{-4}$ \\
\hline SMT, kg & $17.0(1.6)$ & $24.6(3.0)$ & $2.5 \times 10^{-42}$ \\
\hline \multicolumn{4}{|l|}{ Plasma concentration ${ }^{3}$} \\
\hline Leptin, ng/mL & $45.2(23.9)$ & $18.8(12.6)$ & $1.1 \times 10^{-13}$ \\
\hline sOB-R, ng/mL & $20.1(8.2)$ & $21.9(7.2)$ & 0.30 \\
\hline Resistin, ng/mL & $4.0(1.2)$ & $4.2(1.3)$ & 0.10 \\
\hline FABP4, ng/mL & $32.5(11.7)$ & $21.2(7.5)$ & $1.8 \times 10^{-9}$ \\
\hline IL-6, pg/mL & $1.7(0.8)$ & $1.8(0.8)$ & 0.13 \\
\hline Total adiponectin, $\mu \mathrm{g} / \mathrm{mL}$ & $8.3(3.6)$ & $5.7(2.0)$ & $2.5 \times 10^{-5}$ \\
\hline HMW adiponectin, $\mu \mathrm{g} / \mathrm{mL}$ & $4.7(2.2)$ & $2.7(1.5)$ & $3.2 \times 10^{-6}$ \\
\hline MMW adiponectin, $\mu \mathrm{g} / \mathrm{mL}$ & $1.5(0.9)$ & $1.2(0.6)$ & $1.6 \times 10^{-2}$ \\
\hline LMW adiponectin, $\mu \mathrm{g} / \mathrm{mL}$ & $1.9(1.0)$ & $1.6(0.5)$ & $2.0 \times 10^{-2}$ \\
\hline \multicolumn{4}{|l|}{ SAT gene expression ${ }^{2,3}$} \\
\hline Leptin & $1 \times 10^{-3}\left(4 \times 10^{-4}\right)$ & $7 \times 10^{-4}\left(2 \times 10^{-4}\right)$ & $3.7 \times 10^{-17}$ \\
\hline sOB-R & $3 \times 10^{-5}\left(1 \times 10^{-5}\right)$ & $4 \times 10^{-5}\left(1 \times 10^{-5}\right)$ & 0.54 \\
\hline Resistin & $2 \times 10^{-7}\left(2 \times 10^{-7}\right)$ & $7 \times 10^{-8}\left(7 \times 10^{-8}\right)$ & 0.06 \\
\hline FABP4 & $3 \times 10^{-2}\left(6 \times 10^{-3}\right)$ & $3 \times 10^{-2}\left(7 \times 10^{-3}\right)$ & 0.13 \\
\hline IL-6 & $5 \times 10^{-6}\left(3 \times 10^{-6}\right)$ & $4 \times 10^{-6}\left(2 \times 10^{-6}\right)$ & 0.14 \\
\hline Adiponectin & $3 \times 10^{-3}\left(9 \times 10^{-4}\right)$ & $2 \times 10^{-3}\left(9 \times 10^{-4}\right)$ & $4.5 \times 10^{-3}$ \\
\hline
\end{tabular}


Konigorski et al.: Prediction of Circulating Adipokine Levels Based on Body Fat Compartments and Adipose Tissue Gene Expression

\section{Results}

\section{Description of the Participants' Characteristics}

The group of participants consisted of slightly more women (55\%) than men, had an average age of 64.5 years ( $\mathrm{SD}=8.6$ years), a mean BMI of $27.9(\mathrm{SD}=4.1$ ), and a low prevalence of cardiovascular and cardiometabolic diseases (Table 1) despite elevated blood pressure (mean systolic blood pressure of $134.8 \mathrm{~mm} \mathrm{Hg}$ [SD $=15.8 \mathrm{~mm} \mathrm{Hg}$ ] and mean diastolic blood pressure of $80.6 \mathrm{~mm}$ $\mathrm{Hg}[\mathrm{SD}=9.9 \mathrm{~mm} \mathrm{Hg}]$ ). The use of medication corresponded to these statistics: a high percentage of participants took blood pressure-reducing medication, and only a small percentage took antiinflammatory or antidiabetic drugs. All AT measures, plasma levels of leptin, FABP4 and adiponectin, and gene expression of leptin and adiponectin differed among sex-specific subgroups (Table 1). For example, SAT was on average $20.1 \mathrm{~kg}$ (SD = $5.1 \mathrm{~kg}$ ) for women and $14.7 \mathrm{~kg}$ (SD = $4.3 \mathrm{~kg}$ ) for men, and median leptin plasma levels were $45.2 \mu \mathrm{g} / \mathrm{mL}$ (median absolute deviation = $23.9 \mu \mathrm{g} / \mathrm{mL}$ ) in women and $18.8 \mu \mathrm{g} / \mathrm{mL}$ (median absolute deviation $=12.6 \mu \mathrm{g} / \mathrm{mL}$ ) in men.

\section{Variance of Adipokine Concentrations Explained by Body Fat Compartments and SAT Gene Expression}

For the primary aim, we investigated how much of the variance in the biomarker plasma concentrations could be explained overall by VAT mass, SAT mass, SAT gene expression, and their interaction for the respective gene (Table 2). SAT gene expression of the respective adipokine (model 1) explained $48 \%$ of the variance in leptin, but $<10 \%$ of the variance in the remaining adipokines. SAT mass (model 2) explained $76 \%$ of leptin concentrations, $42 \%$ of FABP $4,13 \%$ of sOB-R, and close to $0 \%$ for the remaining adipokines. VAT mass (model 3) explained $15 \%$ for total and HMW adiponectin, $12 \%$ for IL-6, $10 \%$ for MMW adiponectin, and $<10 \%$ for the remaining adipokines.

SAT mass together with SAT gene expression (model 4) explained $81 \%$ for leptin, $45 \%$ for FABP $4,12 \%$ for sOB-R, and close to $0 \%$ for all other adipokines. The interaction between SAT mass and SAT gene expression of the respective gene (model 5) accounted for $30 \%$ of leptin, $22 \%$ of FABP 4 , and $10 \%$ of sOB-R levels, but it did not explain any variance on top of the main effects of SAT gene expression and SAT mass (i.e., in model 6 compared to model 4).

Overall, when SAT gene expression, SAT mass, and VAT mass were considered in combination (model 7), a substantial proportion of the plasma concentration was explained for leptin (adjusted $R^{2}=81 \%$ ) and, albeit to a somewhat smaller extent, for FABP4 (45\%). In contrast, the variance explained by these predictors was low for the remaining adipokines (between 10 and 16\% for sOB-R, IL-6, total, HMW, and MMW adiponectin, and close to $0 \%$ for resistin and LMW adiponectin).

Table 1 (Footnote)

Values are relative frequencies, mean and SD, or ${ }^{3}$ median and median absolute deviation. AT, adipose tissue; CAT, coronary adipose tissue; CPAI, Cambridge Physical Activity Index; FABP4, fatty acid-binding protein 4; HMW, high molecular weight; IL-6, interleukin 6; LMW, low molecular weight; MMW, medium molecular weight; MRI, magnetic resonance imaging; SAT, subcutaneous adipose tissue; SMT, skeletal muscle tissue; sOB-R, soluble leptin receptor; TAT, total adipose tissue; VAT, visceral adipose tissue. ${ }^{1}$ MRI measures do not include arms and head. ${ }^{2}$ Gene expression is shown relative to the housekeeping gene expression in the unit $2^{-\Delta \mathrm{Ct}}$, with higher values representing higher expression levels. $p$ values from hypothesis tests of the null hypothesis that there is no difference between sexes are computed from two-sample $t$ tests of the untransformed variables or of the ${ }^{3}$ log-transformed variables, from ${ }^{4}$ Pearson's asymptotic $\chi^{2}$ tests, or ${ }^{5}$ Fisher's exact tests. 
Konigorski et al.: Prediction of Circulating Adipokine Levels Based on Body Fat

Compartments and Adipose Tissue Gene Expression

Table 2. Variance (adjusted $R^{2}$ ) of the plasma adipokine concentrations explained by body fat compartments and SAT gene expression

\begin{tabular}{|c|c|c|c|c|c|c|c|c|c|c|}
\hline Model & Predictors & Leptin & sOB-R & Resistin & FABP4 & $\begin{array}{l}\text { Total } \\
\text { adiponectin }\end{array}$ & $\begin{array}{l}\text { HMW } \\
\text { adiponectin }\end{array}$ & $\begin{array}{l}\text { MMW } \\
\text { adiponectin }\end{array}$ & $\begin{array}{l}\text { LMW } \\
\text { adiponectin }\end{array}$ & IL-6 \\
\hline 1 & $\mathrm{GE}_{\text {same }}$ & 0.48 & 0 & 0 & 0 & 0.04 & 0.03 & 0.03 & 0 & 0.02 \\
\hline 2 & SAT & 0.76 & 0.13 & 0.01 & 0.42 & 0 & 0 & 0 & 0 & 0.01 \\
\hline 3 & VAT & 0 & 0.06 & 0 & 0 & 0.15 & 0.15 & 0.10 & 0.02 & 0.12 \\
\hline 4 & $\mathrm{GE}_{\text {same, }}, \mathrm{SAT}$ & 0.81 & 0.12 & 0.01 & 0.45 & 0.03 & 0.03 & 0.03 & 0 & 0.02 \\
\hline 5 & $\mathrm{GE}_{\text {same }} \times \mathrm{SAT}$ & 0.30 & 0.10 & 0.02 & 0.22 & 0 & 0 & 0 & 0 & 0 \\
\hline 6 & $\begin{array}{l}\mathrm{GE}_{\text {same }}, \mathrm{SAT} \\
\mathrm{GE}_{\text {same }} \times \mathrm{SAT}\end{array}$ & 0.81 & 0.12 & 0.01 & 0.45 & 0.03 & 0.02 & 0.05 & 0 & 0.04 \\
\hline 7 & $\mathrm{GE}_{\text {same, }}$ SAT, VAT & 0.81 & 0.16 & 0.01 & 0.45 & 0.15 & 0.14 & 0.10 & 0.02 & 0.12 \\
\hline
\end{tabular}

Explained variance (adjusted $R^{2}$ ) of the plasma adipokine concentrations from separate linear regression models for each adipokine and each model, with plasma adipokine concentrations as outcome and the above variables as predictors. Plasma adipokine concentrations, SAT gene expression, VAT, and SAT were log-transformed for analysis. FABP4, fatty acid-binding protein 4; $\mathrm{GE}_{\text {same, }}$ gene expression of the same gene as the respective predicted adipokine; HMW, high molecular weight; IL-6, interleukin 6; LMW, low molecular weight; MMW, medium molecular weight; SAT, subcutaneous adipose tissue; sOB-R, soluble leptin receptor; VAT, visceral adipose tissue.

For a description of the results from sex-stratified analyses, see online supplementary Table S1 and online supplementary text S6.

Variance of Adipokine Concentrations Explained by Additional Personal and

Environmental Determinants

Next, we examined additional determinants (Table 3). Sex alone (model 8) explained $32 \%$ of the variance for leptin levels, $10-20 \%$ for FABP 4 , total, and HMW adiponectin levels, and close to $0 \%$ for the remaining adipokines. When sex was added to gene expression, SAT, and VAT (model 9), it did not or only slightly increase the explained variance in plasma levels (compared to model 7), suggesting that differences between sexes were accounted for by differences in AT mass and gene expression (Table 1).

Regarding the contribution of other factors, the largest increases in the explained variance in adipokine levels in comparison to model 9 were observed as follows: For sOB-R, resistin, FABP4, and HMW adiponectin, the plasma concentration of other adipokines (model 13) increased the explained variance from 16 to $24 \%$, from 1 to $17 \%$, from 49 to $54 \%$, and from 18 to $24 \%$, respectively. For MMW adiponectin and IL-6, the gene expression of other adipokines (model 12) increased the explained variance from 10 to $23 \%$ and from 12 to $21 \%$, respectively. For leptin, total adiponectin, and LMW adiponectin, $<5 \%$ additional variance was explained.

\section{Partial Correlations of Adipokine Concentrations with Body Fat Compartments and SAT}

Gene Expression

Next, we investigated partial correlations between the different body fat compartments and gene expression with adipokine concentrations (Tables 4, 5), and provide here a descriptive comparison of these effect sizes. 
Konigorski et al.: Prediction of Circulating Adipokine Levels Based on Body Fat

Compartments and Adipose Tissue Gene Expression

Table 3. Variance (adjusted $R^{2}$ ) of the plasma adipokine concentrations explained by additional personal and environmental determinants

\begin{tabular}{|c|c|c|c|c|c|c|c|c|c|c|}
\hline Model & Predictors & Leptin & sOB-R & Resistin & FABP4 & $\begin{array}{l}\text { Total } \\
\text { adiponectin }\end{array}$ & $\begin{array}{l}\text { HMW } \\
\text { adiponectin }\end{array}$ & $\begin{array}{l}\text { MMW } \\
\text { adiponectin }\end{array}$ & $\begin{array}{l}\text { LMW } \\
\text { adiponectin }\end{array}$ & IL-6 \\
\hline 8 & sex & 0.32 & 0 & 0.01 & 0.21 & 0.10 & 0.13 & 0.03 & 0.03 & 0.01 \\
\hline 9 & $\mathrm{GE}_{\text {same }}, \mathrm{SAT}, \mathrm{VAT}$, sex & 0.82 & 0.16 & 0.01 & 0.49 & 0.16 & 0.18 & 0.10 & 0.02 & 0.12 \\
\hline 10 & $\begin{array}{l}\mathrm{GE}_{\text {same, }} \mathrm{SAT}, \mathrm{VAT}, \text { sex, } \\
\text { age, occupational training, } \\
\text { physical activity }\end{array}$ & 0.81 & 0.16 & 0.06 & 0.49 & 0.15 & 0.18 & 0.16 & 0.02 & 0.20 \\
\hline 11 & $\begin{array}{l}\mathrm{GE}_{\text {same }} \text { SAT, VAT, sex, } \\
\text { age, occupational training, } \\
\text { physical activity, BMI, WHR, } \\
\text { CAT, TAT }\end{array}$ & 0.82 & 0.16 & 0.04 & 0.50 & 0.16 & 0.17 & 0.14 & 0.01 & 0.20 \\
\hline 12 & $\begin{array}{l}\mathrm{GE}_{\text {same, }} \mathrm{SAT}, \mathrm{VAT}, \text { sex, } \\
\text { age, occupational training, } \\
\text { physical activity, } \mathrm{GE}_{\text {other_1 }} \text {, } \\
\mathrm{GE}_{\text {other_2 }}, \mathrm{GE}_{\text {other_3}}, \mathrm{GE}_{\text {other_4 }} \\
\mathrm{GE}_{\text {other_5 }}\end{array}$ & 0.83 & 0.21 & 0.06 & 0.47 & 0.20 & 0.21 & 0.23 & 0.02 & 0.21 \\
\hline 13 & $\begin{array}{l}\mathrm{GE}_{\text {same, }} \mathrm{SAT}, \mathrm{VAT} \text {, sex, } \\
\text { age, occupational training, } \\
\text { physical activity, } \mathrm{PL}_{\text {other_1 }} \\
\mathrm{PL}_{\text {other_2 }} \mathrm{PL}_{\text {other_3 }}, \mathrm{PL}_{\text {other_4 }} \\
\mathrm{PL}_{\text {other_5 }}\end{array}$ & 0.82 & 0.24 & 0.17 & 0.54 & 0.18 & 0.24 & 0.17 & 0.03 & 0.20 \\
\hline 14 & $\begin{array}{l}\mathrm{GE}_{\text {same, }} \mathrm{SAT}, \mathrm{VAT} \text {, sex, } \\
\text { age, occupational training, } \\
\text { physical activity, } \\
\text { employment status, partner } \\
\text { status, smoking status, SES, } \\
\text { diabetes status }\end{array}$ & 0.82 & 0.15 & 0.03 & 0.46 & 0.17 & 0.23 & 0.13 & 0 & 0.19 \\
\hline
\end{tabular}

Explained variance (adjusted $R^{2}$ ) of the plasma adipokine concentrations from separate linear regression models for each adipokine and each model, with plasma adipokine concentrations as outcome and the above variables as predictors. Plasma adipokine concentrations, SAT gene expression, VAT, and SAT were log-transformed for analysis. BMI, body mass index; CAT, coronary adipose tissue; FABP4, fatty acid-binding protein $4 ; \mathrm{GE}_{\text {other } 1 . . .5}$, gene expression of all five genes other than the predicted adipokine; $\mathrm{GE}_{\text {same, }}$ gene expression of the same gene as the respective predicted adipokine; HMW, high molecular weight; IL-6, interleukin 6; LMW, low molecular weight; MMW, medium molecular weight; $\mathrm{PL}_{\mathrm{other} \_1 . .5}$, circulating concentrations of all 5 adipokines other than the predicted adipokine; SAT, subcutaneous adipose tissue; SES, socioeconomic status; sOB-R, soluble leptin receptor; TAT, total adipose tissue; VAT, visceral adipose tissue; WHR, waist-hip ratio.

Regarding a comparison of AT compartments (Table 4), for leptin and FABP4 plasma levels, the highest partial correlations were observed with TAT and SAT, which were larger compared to the correlations with VAT. For sOB-R, resistin, IL-6, total, HMW, and LMW adiponectin, the correlations of each adipokine with SAT, VAT, and TAT were of similar size. For MMW adiponectin, the correlation with VAT was slightly larger compared to SAT and TAT. CAT showed smaller or equal correlations compared to VAT, SAT, and TAT for all investigated adipokines.

Regarding SAT gene expression (Table 5), leptin gene expression was moderately correlated with leptin concentration. Correlations between SAT gene expression and plasma levels were weak for all other adipokines.

Regarding a comparison of AT mass and SAT gene expression, AT mass showed stronger or similar associations for all adipokines. Analyses stratifying by sex instead of adjusting for sex indicated some differences for some AT measures and some adipokines (e.g., partial correlation of VAT with circulating leptin was $r=0.48$ in women and $r=0.71 \mathrm{in}$ men); however, none of these sex differences were statistically significant (online suppl. Tables S2 and S3). 


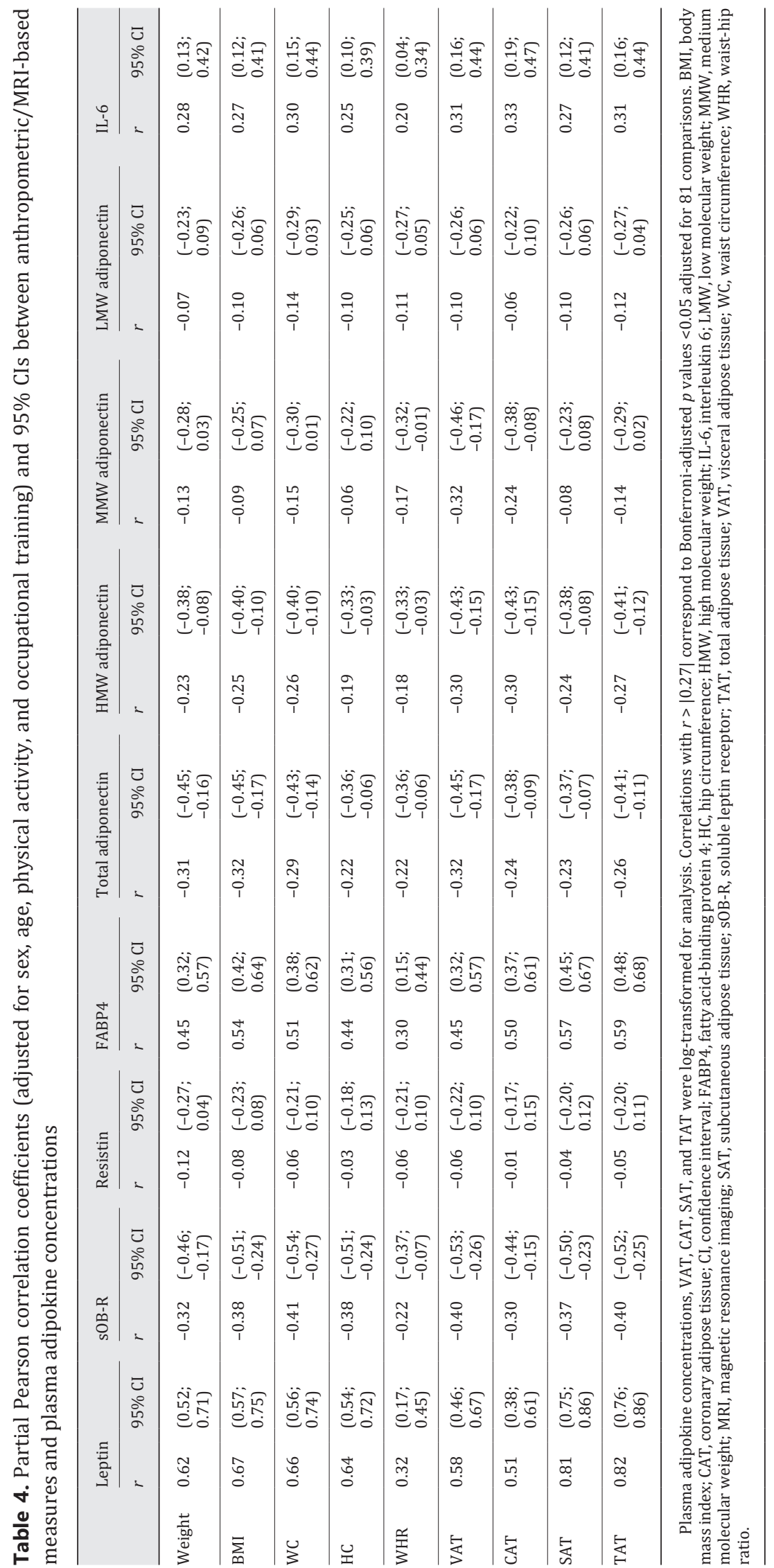


Table 5. Partial Pearson correlation coefficients $r$ (adjusted for sex, age, physical activity, and occupational training) and 95\% CIs between plasma adipokine concentrations and SAT gene expressions
Konigorski et al.: Prediction of Circulating Adipokine Levels Based on Body Fat Compartments and Adipose Tissue Gene Expression

\begin{tabular}{lrc}
\hline Biomarker & \multicolumn{1}{c}{$r$} & \multicolumn{1}{c}{$95 \% \mathrm{CI}$} \\
\hline Leptin & 0.52 & $0.40 ; 0.63$ \\
sOB-R & -0.05 & $-0.20 ; 0.11$ \\
Resistin & 0.08 & $-0.08 ; 0.24$ \\
FABP4 & 0.02 & $-0.13 ; 0.18$ \\
Total adiponectin & 0.15 & $-0.01 ; 0.30$ \\
HMW adiponectin & 0.13 & $-0.03 ; 0.28$ \\
MMW adiponectin & 0.16 & $0 ; 0.31$ \\
LMW adiponectin & -0.03 & $-0.19 ; 0.13$ \\
IL-6 & 0.19 & $0.03 ; 0.34$ \\
\hline
\end{tabular}

Plasma adipokine concentrations and SAT gene expressions were log-transformed for analysis. Correlations $r>|0.19|$ correspond to Bonferroni-adjusted $p$ values $<0.05$ adjusted for 9 comparisons. CI, confidence interval; FABP4, fatty acid-binding protein 4; HMW, high molecular weight; IL-6, interleukin 6; LMW, low molecular weight; MMW, medium molecular weight; SAT, subcutaneous adipose tissue; sOB-R, soluble leptin receptor.

In comparisons of MRI quantification with traditional anthropometric measures (Table 4), for leptin and MMW adiponectin, MRI AT measures showed stronger correlations with plasma levels compared to the traditional measures, whereas for all remaining adipokines, correlations with MRI measures were in a similar range as their correlations with traditional measures. Among the traditional surrogate measures for adiposity and fat distribution, correlations of plasma levels with BMI and with WC were similar for all markers.

For background information regarding the correlations between gene expression, plasma levels, and AT measures and for results of the sensitivity analyses (which did not change any of the conclusions), see online supplementary text S6 and online supplementary Tables S4-S11.

\section{Discussion}

This study investigated to what extent plasma adipokine concentrations are determined by MRI-based quantification of AT compartments and by gene expression in SAT. For leptin and FABP4 concentrations, a large and moderate part of their variance was explained, respectively. However, surprisingly little variance was explained for adiponectin, sOB-R, resistin, and IL-6. While MRI-based measures yielded an improvement compared to standard anthropometric measures for the prediction of circulating levels for leptin [19] and MMW adiponectin, they yielded similar effect estimates for all other adipokines [20,48,49]. Since our effect estimates for the traditional anthropometric measures and, where available, for estimates of total body fat are similar to reports in the literature [4-7, 19, 21, 48-53], these results do not support our hypothesis that a large part of the variance of adipokine levels can be explained by MRI-derived measures of body fat and SAT gene expression, except for leptin and FABP4. In general, AT mass was the main contributor to the explained variance and played a much larger role than SAT gene expression [54]. Regarding the AT compartments - even though their correlation has to be considered in the interpretation of results SAT seems to play a larger role for leptin $[19,55]$ compared to VAT, and interestingly little or no differences were observed for all other adipokines [48]. CAT seems to play a lesser role compared to VAT and SAT in explaining the plasma levels of all investigated adipokines, 
Konigorski et al.: Prediction of Circulating Adipokine Levels Based on Body Fat Compartments and Adipose Tissue Gene Expression

which might be explained by the small amount of CAT in comparison to the other compartments. For an interpretation of these descriptive comparisons, we want to stress that in line with our study aims, we focused on the estimation of effect sizes and deliberately did not statistically test for differences of effects between AT compartments (and gene expression measures), which would need to consider the multiple testing of the different compartments and adipokines (e.g., see legends of Tables 4 and 5) and could be performed in future studies.

Regarding leptin, a large proportion of the variance (76\%) of its circulating levels was explained by SAT. While gene expression explained $48 \%$ when considered alone [24, 32], it contributed only little additional information when added to SAT mass. These data confirm that leptin is primarily a biomarker for SAT mass $[19,55]$. However, SAT mass was also weakly associated with leptin gene expression (online suppl. Table S7), so that the estimated effect of SAT on circulating leptin might also contain part of the effect of leptin gene expression. The association of VAT mass with leptin levels was much smaller $[19,55]$. Some of the remaining unexplained variance of leptin levels might be explained by VAT gene expression, which was not assessed in this study. Regarding FABP4, which acts as a carrier for fatty acids and is primarily expressed in adipocytes and macrophages, close to $50 \%$ of its variance was explained, with a slightly higher contribution of SAT compared to VAT. Gene expression did not contribute at all to the explained variance. Thus, somewhat similar as for leptin, these data suggest that FABP4 is a biomarker for AT mass although more than half of the variance remained unexplained [52]. sOB-R is the main leptin-binding protein whose expression has been reported in multiple other tissues besides AT [10]. In our analysis, SAT and VAT only explained $16 \%$ variance of its plasma levels, while gene expression did not contribute at all. For adiponectin, which is predominantly synthesized and secreted from adipocytes in VAT and SAT [4, 27], VAT explained slightly more of its variance compared to SAT [20]. However, the explained variance was very low and only about $10-15 \%$ for total, HMW, and MMW adiponectin and 2\% for LMW adiponectin $[6,48,56$, 57]. This is surprising, given that adiponectin is often considered "the" classical adipokine. For resistin, which is expressed at lower levels in adipocytes but at higher levels in circulating blood monocytes [7], AT and gene expression did not predict its circulating levels in our study [14,21]. This raises the question as to whether resistin can truly be considered an adipokine in humans. Finally, regarding IL-6, which is secreted by multiple cell types including monocytes, macrophages, and adipocytes [4], our results suggest that adiposity explains only a small proportion of its circulating levels in humans $[8,51,53]$, in contrary to the established notion that obesity is associated with low-grade subclinical inflammation [4]. Including further inflammatory cytokines such as TNF- $\alpha$ as well as information on inflammatory processes and AT cell type composition in follow-up studies could enable a more detailed investigation of the obesity-inflammation link and separation of the effects of AT compartments on the population level. We anticipate that the cell type composition of AT and other measures of inflammation might primarily act as a mediator of the obesity-adipokine association, so that our estimates provide an overall estimate of how much variance of IL- 6 levels can be explained by AT, of which parts might be further explained by inflammatory processes.

It is not clear why so little variance of plasma levels was explained by AT and SAT gene expression in our study for adiponectin, SOB-R, resistin, and IL-6. Measurement error as an explanation appears unlikely since well-established assays were used, quality measures were good, and the correlations between adipokine levels and traditional anthropometric measures such as BMI and WC were similar to those reported in other studies [4-7, 19, 21, 48-53] for all adipokines. Furthermore, we observed a substantial correlation of AT measures with leptin. Also, while protein degradation, different half-lives of the investigated adipokines, and fasting status may affect adipokine concentrations, previous studies have shown a good reliability of plasma concentration estimates over time, robustness against fasting status, and we confirmed the robustness of adipokine concentrations and SAT gene expression against fasting status by 
Konigorski et al.: Prediction of Circulating Adipokine Levels Based on Body Fat

Compartments and Adipose Tissue Gene Expression

sensitivity checks in our study (online suppl. texts S4 and S5). Also, the observed associations between AT mass and adipokine plasma concentrations as well as gene expression were not affected by differences in blood pressure, and the partial correlations in Tables 4 and 5 were very similar when further adjusting for systolic and diastolic blood pressure (results not shown). Similarly, even if there was some indication in further sensitivity analyses that some adipokine levels differ between probands taking drugs of different medication classes (e.g., higher IL-6 levels in participants taking anti-inflammatory drugs), the partial correlations in Tables 4 and 5 were very similar when stratifying or adjusting for medication use (results not shown). Further, the results were similar when crude estimates of absolute adipokine quantities in plasma were analyzed. Hence, there is no indication that the weak observed associations between AT mass and plasma concentrations were due to the fact that plasma concentrations are relative to blood volume (which depends on height and also AT mass). Since our results were almost identical with and without adjusting for height, height ${ }^{2}$, height ${ }^{3}$, or SMT, there is no indication that the AT changes qualitatively in its metabolic activity with increasing relative AT mass, in contrast to what could be hypothesized from the results of previous smallscale studies [58] and even though we observed an association of AT mass and gene expression for some adipokines. Finally, the additional predictors investigated in our study added only little explained variance, and also when considering complex interaction effects between all measures in further exploratory analyses (online suppl. text S7; online suppl. Table S12), no or only little additional variance of adipokine levels could be explained.

We speculate whether other biological factors, e.g., posttranscriptional modifications and regulatory elements, may account for a large part of the variance in plasma levels of adipokines other than leptin and FABP4. Also, some adipokines such as IL-6 and FABP4 are also expressed and secreted into plasma from other tissues $[59,60]$. Furthermore, other lifestyle factors such as diet [24], clinical parameters, other circulating proteins [61], and genetic markers that do not affect mRNA abundance but circulating levels through other processes might be interesting for future studies. Finally, more detailed sex-stratified analyses could be interesting for follow-up. In this study, we focused on sex-adjusted analyses with the underlying reasoning that sex may affect AT mass, but AT is the primary tissue from where the adipokines are secreted so that sex has only an indirect association with adipokine levels.

Without the assessment of VAT gene expression and secretion rates from SAT and VAT [62], parts of the overall molecular picture remain unclear. However, assessing VAT in a population-based study is rarely possible, and VAT gene expression measured after bariatric or other surgeries might not allow for a valid approximation of the metabolic activity in the general population. Since adipokine secretion as well as their biological function can be regulated on the transcriptional or posttranscriptional level $[59,60]$, gene expression might not be the best proxy for the metabolic activity of AT and differ from the secretion rate. As further limitations, we investigated probands from the general German population with exclusion of severe disease. Hence, our results might not generalize to other populations or patients. Furthermore, our results can only provide hints as to how much variance of other adipokines not investigated here can be explained by AT and gene expression. Since MRI protocols but not magnetic resonance spectroscopy were performed, further body compartments such as ectopic fat [63] could not be investigated. Finally, another limitation of our study is that obesity measures were only assessed cross-sectionally and longitudinal information such as recent weight changes could not be considered.

In conclusion, our study shows that while for leptin, most of the variance in plasma concentrations can be explained by AT mass (particularly SAT mass) and SAT gene expression, this is less so for FABP4. In contrast and counterintuitively, most of the variance in the plasma concentrations of the so-called adipokines sOB-R, resistin, adiponectin, and IL- 6 cannot be explained by AT mass or SAT gene expression. Hence, imaging-based assessment of body 
Konigorski et al.: Prediction of Circulating Adipokine Levels Based on Body Fat

Compartments and Adipose Tissue Gene Expression

compartments only yields improvements for the prediction of some adipokines. These data suggest that other factors or interactions with other factors are the main determinants of these plasma concentrations, and that there is not a straightforward path from obesity to chronic diseases through adipokine levels and the tissue secreting them. While our findings do not contradict a potential role of these adipokines in disease development, their circulating concentrations are unlikely to individually mediate the association between adiposity and disease risk observed in epidemiological studies to a large extent. Future studies on such mediation effects are warranted and should also consider the interplay of adipokines, their downstream products, and regulatory markers.

\section{Acknowledgements}

The authors thank the participants of the EPIC Potsdam substudy, the teams at EPIC Potsdam and EPIC Heidelberg for the data handling of the MRI data, and the staff of the study center EPIC Potsdam for their work. They are grateful to Ellen Kohlsdorf for data handling, to Sarah Moreno Garcia and Henning Damm for sample handling and for performing the ELISA and PCR experiments, and to Martin Küper for accurate performance of the MRI scans.

\section{Statement of Ethics}

The study was approved by the ethics committee of the medical association of the state of Brandenburg (Germany), and all participants gave written informed consent.

\section{Disclosure Statement}

The authors have no conflicts of interest to declare.

\section{Funding Sources}

S. Konigorski was partly supported by funds granted by the Helmholtz Association as part of the portfolio topic "Metabolic Dysfunction."

\section{References}

1 World Health Organization. Obesity: preventing and managing the global epidemic. Report of a WHO consultation. World Health Organ Tech Rep Ser. 2000;894:i-xii, 1-253.

2 Fasshauer M, Blüher M. Adipokines in health and disease. Trends Pharmacol Sci. 2015 Jul;36(7):461-70.

3 Himbert C, Delphan M, Scherer D, Bowers LW, Hursting S, Ulrich CM. Signals from the adipose microenvironment and the obesity-cancer link - a systematic review. Cancer Prev Res (Phila). 2017 Sep;10(9):494-506.

4 Pischon T. Use of obesity biomarkers in cardiovascular epidemiology. Dis Markers. 2009;26(5-6):247-63.

5 Aleksandrova K, Boeing H, Jenab M, Bueno-de-Mesquita HB, Jansen E, van Duijnhoven FJ, et al. Leptin and soluble leptin receptor in risk of colorectal cancer in the European Prospective Investigation into Cancer and Nutrition cohort. Cancer Res. 2012 Oct;72(20):5328-37.

6 Aleksandrova K, Boeing H, Jenab M, Bueno-de-Mesquita HB, Jansen E, van Duijnhoven FJ, et al. Total and highmolecular weight adiponectin and risk of colorectal cancer: the European Prospective Investigation into Cancer and Nutrition Study. Carcinogenesis. 2012 Jun;33(6):1211-8.

7 Norata GD, Ongari M, Garlaschelli K, Raselli S, Grigore L, Catapano AL. Plasma resistin levels correlate with determinants of the metabolic syndrome. Eur J Endocrinol. 2007 Feb;156(2):279-84. 
Konigorski et al.: Prediction of Circulating Adipokine Levels Based on Body Fat

Compartments and Adipose Tissue Gene Expression

8 Pai JK, Pischon T, Ma J, Manson JE, Hankinson SE, Joshipura K, et al. Inflammatory markers and the risk of coronary heart disease in men and women. N Engl J Med. 2004 Dec;351(25):2599-610.

9 Friedman J. The long road to leptin. J Clin Invest. 2016 Dec;126(12):4727-34.

10 Zastrow O, Seidel B, Kiess W, Thiery J, Keller E, Böttner A, et al. The soluble leptin receptor is crucial for leptin action: evidence from clinical and experimental data. Int J Obes Relat Metab Disord. 2003 Dec;27(12):1472-8.

11 Aleksandrova K, Mozaffarian D, Pischon T. Addressing the perfect storm: biomarkers in obesity and pathophysiology of cardiometabolic risk. Clin Chem. 2018 Jan;64(1):142-53.

12 Kern PA, Ranganathan S, Li C, Wood L, Ranganathan G. Adipose tissue tumor necrosis factor and interleukin-6 expression in human obesity and insulin resistance. Am J Physiol Endocrinol Metab. 2001 May;280(5):E745-51.

13 Pischon T, Bamberger CM, Kratzsch J, Zyriax BC, Algenstaedt P, Boeing H, et al. Association of plasma resistin levels with coronary heart disease in women. Obes Res. 2005 Oct;13(10):1764-71.

14 Weikert C, Westphal S, Berger K, Dierkes J, Möhlig M, Spranger J, et al. Plasma resistin levels and risk of myocardial infarction and ischemic stroke. J Clin Endocrinol Metab. 2008 Jul; 93(7):2647-53.

15 Ibrahim MM. Subcutaneous and visceral adipose tissue: structural and functional differences. Obes Rev. 2010 Jan;11(1):11-8.

16 Wajchenberg BL. Subcutaneous and visceral adipose tissue: their relation to the metabolic syndrome. Endocr Rev. 2000 Dec;21(6):697-738.

17 Liesenfeld DB, Grapov D, Fahrmann JF, Salou M, Scherer D, Toth R, et al. Metabolomics and transcriptomics identify pathway differences between visceral and subcutaneous adipose tissue in colorectal cancer patients: the ColoCare study. Am J Clin Nutr. 2015 Aug;102(2):433-43.

18 Karlsson AK, Kullberg J, Stokland E, Allvin K, Gronowitz E, Svensson PA, et al. Measurements of total and regional body composition in preschool children: A comparison of MRI, DXA, and anthropometric data. Obesity (Silver Spring). 2013 May;21(5):1018-24.

19 Arnardottir ES, Maislin G, Jackson N, Schwab RJ, Benediktsdottir B, Teff K, et al. The role of obesity, different fat compartments and sleep apnea severity in circulating leptin levels: the Icelandic Sleep Apnea Cohort study. Int J Obes. 2013 Jun;37(6):835-42.

20 Maahs DM, Ogden LG, Snell-Bergeon JK, Kinney GL, Wadwa RP, Hokanson JE, et al. Determinants of serum adiponectin in persons with and without type 1 diabetes. Am J Epidemiol. 2007 Sep;166(6):731-40.

21 Won JC, Park CY, Lee WY, Lee ES, Oh SW, Park SW. Association of plasma levels of resistin with subcutaneous fat mass and markers of inflammation but not with metabolic determinants or insulin resistance. J Korean Med Sci. 2009 Aug;24(4):695-700.

22 Balaž M, Ukropcova B, Kurdiova T, Vlcek M, Surova M, Krumpolec P, et al. Improved adipose tissue metabolism after 5-year growth hormone replacement therapy in growth hormone deficient adults: the role of zinc- $\alpha 2$ glycoprotein. Adipocyte. 2014 Dec;4(2):113-22.

23 Bjermo H, Iggman D, Kullberg J, Dahlman I, Johansson L, Persson L, et al. Effects of n-6 PUFAs compared with SFAs on liver fat, lipoproteins, and inflammation in abdominal obesity: a randomized controlled trial. Am J Clin Nutr. 2012 May;95(5):1003-12.

24 Campbell KL, Foster-Schubert KE, Makar KW, Kratz M, Hagman D, Schur EA, et al. Gene expression changes in adipose tissue with diet- and/or exercise-induced weight loss. Cancer Prev Res (Phila). 2013 Mar;6(3):21731.

25 Ceperuelo-Mallafré V, Näf S, Escoté X, Caubet E, Gomez JM, Miranda M, et al. Circulating and adipose tissue gene expression of zinc-alpha2-glycoprotein in obesity: its relationship with adipokine and lipolytic gene markers in subcutaneous and visceral fat. J Clin Endocrinol Metab. 2009 Dec;94(12):5062-9.

26 Echiburú B, Pérez-Bravo F, Galgani JE, Sandoval D, Saldías C, Crisosto N, et al. Enlarged adipocytes in subcutaneous adipose tissue associated to hyperandrogenism and visceral adipose tissue volume in women with polycystic ovary syndrome. Steroids. 2018 Feb;130:15-21.

27 Fredriksson J, Carlsson E, Orho-Melander M, Groop L, Ridderstråle M. A polymorphism in the adiponectin gene influences adiponectin expression levels in visceral fat in obese subjects. Int J Obes. 2006 Feb;30(2):226-32.

28 Goldstone AP, Brynes AE, Thomas EL, Bell JD, Frost G, Holland A, et al. Resting metabolic rate, plasma leptin concentrations, leptin receptor expression, and adipose tissue measured by whole-body magnetic resonance imaging in women with Prader-Willi syndrome. Am J Clin Nutr. 2002 Mar; 75(3):468-75.

29 Kjær TN, Ornstrup MJ, Poulsen MM, Stødkilde-Jørgensen H, Jessen N, Jørgensen JO, et al. No beneficial effects of resveratrol on the metabolic syndrome: a randomized placebo-controlled clinical trial. J Clin Endocrinol Metab. 2017 May;102(5):1642-51.

30 Kursawe R, Dixit VD, Scherer PE, Santoro N, Narayan D, Gordillo R, et al. A role of the inflammasome in the low storage capacity of the abdominal subcutaneous adipose tissue in obese adolescents. Diabetes. 2016 Mar; 65(3):610-8.

31 Kursawe R, Narayan D, Cali AM, Shaw M, Pierpont B, Shulman GI, et al. Downregulation of ADIPOQ and PPAR 2 gene expression in subcutaneous adipose tissue of obese adolescents with hepatic steatosis. Obesity (Silver Spring). 2010 Oct;18(10):1911-7.

32 Lee S, Norheim F, Langleite TM, Gulseth HL, Birkeland KI, Drevon CA. Effects of long-term exercise on plasma adipokine levels and inflammation-related gene expression in subcutaneous adipose tissue in sedentary dysglycaemic, overweight men and sedentary normoglycaemic men of healthy weight. Diabetologia. 2019 Jun; 62(6):1048-64. 
Konigorski et al.: Prediction of Circulating Adipokine Levels Based on Body Fat

Compartments and Adipose Tissue Gene Expression

33 Markova M, Pivovarova O, Hornemann S, Sucher S, Frahnow T, Wegner K, et al. Isocaloric diets high in animal or plant protein reduce liver fat and inflammation in individuals with type 2 diabetes. Gastroenterology. 2017 Feb;152(3):571-585.e8.

34 Pietiläinen KH, Kannisto K, Korsheninnikova E, Rissanen A, Kaprio J, Ehrenborg E, et al. Acquired obesity increases CD68 and tumor necrosis factor-alpha and decreases adiponectin gene expression in adipose tissue: a study in monozygotic twins. J Clin Endocrinol Metab. 2006 Jul;91(7):2776-81.

35 Reeds DN, Mohammed BS, Klein S, Boswell CB, Young VL. Metabolic and structural effects of phosphatidylcholine and deoxycholate injections on subcutaneous fat: a randomized, controlled trial. Aesthet Surg J. 2013 Mar;33(3):400-8.

36 Sutinen J, Korsheninnikova E, Funahashi T, Matsuzawa Y, Nyman T, Yki-Järvinen H. Circulating concentration of adiponectin and its expression in subcutaneous adipose tissue in patients with highly active antiretroviral therapy-associated lipodystrophy. J Clin Endocrinol Metab. 2003 Apr;88(4):1907-10.

37 Vettor R, Mingrone G, Manco M, Granzotto M, Milan G, Scarda A, et al. Reduced expression of uncoupling proteins-2 and -3 in adipose tissue in post-obese patients submitted to biliopancreatic diversion. Eur J Endocrinol. 2003 May;148(5):543-50.

38 Boeing H, Wahrendorf J, Becker N. EPIC-Germany - a source for studies into diet and risk of chronic diseases. European Investigation into Cancer and Nutrition. Ann Nutr Metab. 1999;43(4):195-204.

39 Riboli E, Kaaks R. The EPIC Project: rationale and study design. European Prospective Investigation into Cancer and Nutrition. Int J Epidemiol. 1997;26(Suppl 1):S6-14.

40 World Health Organization. Physical status: the use and interpretation of anthropometry. Report of a WHO Expert Committee. World Health Organ Tech Rep Ser. 1995;854:1-452.

41 Neamat-Allah J, Wald D, Hüsing A, Teucher B, Wendt A, Delorme S, et al. Validation of anthropometric indices of adiposity against whole-body magnetic resonance imaging - a study within the German European Prospective Investigation into Cancer and Nutrition (EPIC) cohorts. PLoS One. 2014 Mar;9(3):e91586.

42 Wald D, Teucher B, Dinkel J, Kaaks R, Delorme S, Boeing H, et al. Automatic quantification of subcutaneous and visceral adipose tissue from whole-body magnetic resonance images suitable for large cohort studies. J Magn Reson Imaging. 2012 Dec;36(6):1421-34.

43 Burton RF. Measures of adiposity: the inappropriate use of the fat mass index. Int J Obes. 2010 Jan;34(1):213.

44 VanItallie TB, Yang MU, Heymsfield SB, Funk RC, Boileau RA. Height-normalized indices of the body's fat-free mass and fat mass: potentially useful indicators of nutritional status. Am J Clin Nutr. 1990 Dec;52(6):953-9.

45 Wells JC. Historical cohort studies and the early origins of disease hypothesis: making sense of the evidence. Proc Nutr Soc. 2009 May;68(2):179-88.

46 Livak KJ, Schmittgen TD. Analysis of relative gene expression data using real-time quantitative PCR and the 2(-Delta Delta C(T)) Method. Methods. 2001 Dec;25(4):402-8.

47 R Core Team. The R Project for Statistical Computing. Vienna: R Foundation for Statistical Computing; 2016. https://www.R-project.org.

48 Frederiksen L, Nielsen TL, Wraae K, Hagen C, Frystyk J, Flyvbjerg A, et al. Subcutaneous rather than visceral adipose tissue is associated with adiponectin levels and insulin resistance in young men. J Clin Endocrinol Metab. 2009 0ct;94(10):4010-5.

49 Schlecht I, Fischer B, Behrens G, Leitzmann MF. Relations of visceral and abdominal subcutaneous adipose tissue, body mass index, and waist circumference to serum concentrations of parameters of chronic inflammation. Obes Facts. 2016;9(3):144-57.

50 Aleksandrova K, Drogan D, Boeing H, Jenab M, Bas Bueno-de-Mesquita H, Jansen E, et al. Adiposity, mediating biomarkers and risk of colon cancer in the European prospective investigation into cancer and nutrition study. Int J Cancer. 2014 Feb;134(3):612-21.

51 Bennermo M, Nordin M, Lundman P, Boqvist S, Held C, Samnegård A, et al. Genetic and environmental influences on the plasma interleukin- 6 concentration in patients with a recent myocardial infarction: a casecontrol study. J Interferon Cytokine Res. $2011 \mathrm{Feb}$;31(2):259-64.

52 Ishimura S, Furuhashi M, Watanabe Y, Hoshina K, Fuseya T, Mita T, et al. Circulating levels of fatty acid-binding protein family and metabolic phenotype in the general population. PLoS One. 2013 Nov;8(11):e81318.

53 Marques-Vidal P, Bochud M, Bastardot F, Lüscher T, Ferrero F, Gaspoz JM, et al. Levels and determinants of inflammatory biomarkers in a Swiss population-based sample (CoLaus study). PLoS One. 2011; 6(6):e21002.

54 Spoto B, Di Betta E, Mattace-Raso F, Sijbrands E, Vilardi A, Parlongo RM, et al. Pro- and anti-inflammatory cytokine gene expression in subcutaneous and visceral fat in severe obesity. Nutr Metab Cardiovasc Dis. 2014 Oct;24(10):1137-43.

55 Neeland IJ, Ayers CR, Rohatgi AK, Turer AT, Berry JD, Das SR, et al. Associations of visceral and abdominal subcutaneous adipose tissue with markers of cardiac and metabolic risk in obese adults. Obesity (Silver Spring). 2013 Sep;21(9):E439-47.

56 Pischon T, Girman CJ, Hotamisligil GS, Rifai N, Hu FB, Rimm EB. Plasma adiponectin levels and risk of myocardial infarction in men. JAMA. 2004 Apr;291(14):1730-7.

57 Koska J, Stefan N, Permana PA, Weyer C, Sonoda M, Bogardus C, et al. Increased fat accumulation in liver may link insulin resistance with subcutaneous abdominal adipocyte enlargement, visceral adiposity, and hypoadiponectinemia in obese individuals. Am J Clin Nutr. 2008 Feb;87(2):295-302. 
58 Skurk T, Alberti-Huber C, Herder C, Hauner H. Relationship between adipocyte size and adipokine expression and secretion. J Clin Endocrinol Metab. 2007 Mar;92(3):1023-33.

59 Hotamisligil GS, Bernlohr DA. Metabolic functions of FABPs - mechanisms and therapeutic implications. Nat Rev Endocrinol. 2015 0ct;11(10):592-605.

60 Hunter CA, Jones SA. IL-6 as a keystone cytokine in health and disease. Nat Immunol. 2015 May;16(5):448-57.

61 Eichelmann F, Rudovich N, Pfeiffer AF, Schulze MB, Giuseppe RD, Boeing H, et al. Novel adipokines: methodological utility in human obesity research. Int J Obes. 2017 Jun;41(6):976-81.

62 Fain JN, Madan AK, Hiler ML, Cheema P, Bahouth SW. Comparison of the release of adipokines by adipose tissue, adipose tissue matrix, and adipocytes from visceral and subcutaneous abdominal adipose tissues of obese humans. Endocrinology. 2004 May;145(5):2273-82.

63 Snel M, Jonker JT, Schoones J, Lamb H, de Roos A, Pijl H, et al. Ectopic fat and insulin resistance: pathophysiology and effect of diet and lifestyle interventions. Int J Endocrinol. 2012;2012:983814. 